\title{
A color study on the packaging design of Korean brand cosmetics -Focusing on affordable brands for female consumers-
}

\author{
FANG WEN ${ }^{1}$ a, Meng-jun Huang ${ }^{2}$ b* $^{*}$ \\ ${ }^{1}$ Yichun University, School of Fine Arts and Design Yichun. Jiangxi \\ ${ }^{2}$ Xinyu University, School of Art, Xinyu. jiangxi
}

\begin{abstract}
Cosmetics are essential items in the daily life of modern women. With the improvement of living standards, people have higher and higher requirements for cosmetics. Color is the most sensitive part of people's visual experience. Color design plays an important role in many fields. For successful product packaging, the perfect combination of physical and psychological functions perfectly reflects the characteristics of the product and can attract consumers' attention. In the face of fierce competition, only outer packaging with clear visual characteristics can attract consumers. This research mainly studies the color design of cosmetic packaging design from the perspective of female consumers, and analyzes and summarizes the color design of Korean cheap cosmetics packaging. Use the KSCA program to analyze the color design of the brand, and then perform further analysis by displaying the extracted color values on the IRI image scale. After selecting the cosmetic brand to be studied, use the KSCA program to analyze the color design of the brand, and then perform further analysis by displaying the extracted color values on the IRI image scale. The research results show that: (1) There is no significant difference in the packaging color design of the three brands, and the essence is the brand concept. The color vision rate is not high. The three brands are mainly large and bright background colors, and are designed with fresh green, yellow and orange to bring consumers a clean, natural and bright feeling. The design of these three cosmetics brands has left a deep impression on consumers through the design and impression of cosmetics. (2) In terms of vision and wisdom, the most common color scheme of Korean cosmetics brands is to separate colors similar to complementary colors. Mainly used in warm color series. According to different series, different colors are designed, and the young series usually use bright and bright colors as the primary colors, giving people a fresh, cute, natural and soft feeling. Series emphasizing individuality and efficiency usually use dark colors such as black, red and purple as primary colors, giving people a sense of elegance, mystery and nobility. These color designs can help consumers intuitively choose the attributes of their products through color.
\end{abstract}

\section{Research Background and Purpose}

Cosmetics are an indispensable item in the daily life of a modern woman, in addition to giving women beauty, they increase their confidence and are considered a polite expression at formal events. For many female consumers, makeup habits are very common, and the appearance is very happy to decorate a beautiful appearance (Gao Xianghe, 2017). Taking China as an example, according to statistics from the International Trade Bureau, China was about Imported $\$ 850$ million of cosmetics, the country is growing positively compared to the previous year, people are increasingly demanding cosmetics, color is the most sensitive part of people's visual experience, and color design plays an important role in many fields. For successful product packaging, the perfect combination of physical and psychological functions perfectly characterizes the product and can attract consumer attention. Faced with fierce competition, only outer packaging with clear visual characteristics can attract consumers. For Rivlin \& Weiner, color language has the effect of stimulating the emotions of consumers. In completely different color environments, people's physiological and psychological reactions are very different. For example, black, purple and red environments can make people feel gloomy and dull, while sky blue, lime green and bright yellow environments can make people feel comfortable easily. Many cosmetic brands have recognized the important role of color in creating a brand's visual image, and have consciously started to create their own brand colors and increase brand awareness and value. Therefore, it is very necessary to study color design in cosmetic packaging design.

The purpose of this paper is to explore the design elements and color design of Chinese and Korean cosmetic packaging design, summarize the rules, apply them in practice, and propose the direction and proposal of 
cosmetic packaging design innovation for Chinese cosmetic brands.

\section{Research method and scope}

This study mainly studies the color design of cosmetic packaging design from the perspective of female consumers, and analyzes and summarizes the packaging color design with cosmetic examples from various countries. The specific research method is as follows.

(1) Literature analysis method: Literature analysis method collects literature including Chinese and Korean cosmetics and industry profiles, brand and packaging color design.

(2) Case analysis method: After selecting the cosmetic brand to be studied, use the Korean Standard Color Analysis (KSCA) program to analyze the brand's color design, and then perform further analysis by displaying the extracted color values on the IRI image scale. After selecting a cosmetic brand to study, use the Korean Standard Color Analysis (KSCA) program to analyze the brand's color design, then perform further analysis by displaying the extracted color values on the IRI image scale.

\subsection{Hue\&Tone 120}

Hue\&Tone 120 color system made a simple color scheme based on the Korean feel. The achromatic color is divided into 10 levels according to the brightness, and the chromatic color consists of 110 colors and 20 colors with 10 levels of color and 11 levels of hue (figure 1)

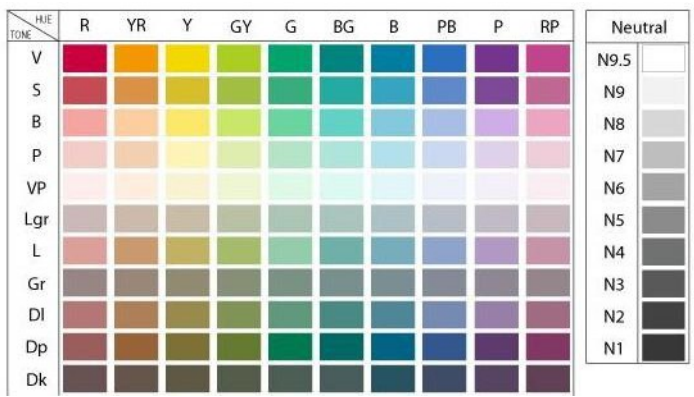

figure 1: Hue\&Tone 120 Source: I.R.I. Color Lab

\subsection{I.R. I image scale}

The I.R.I image scale was obtained by having Koreans evaluate Hue\&Tone 120 colors. It is an image space created to capture the position of color by returning these two criteria to the coordinates of the XY axis, dynamic, static, soft, and hard. Monochrome and adjectives can colorize the image of the adjective in detail at each position. Use color as an adjective. (figure 2)

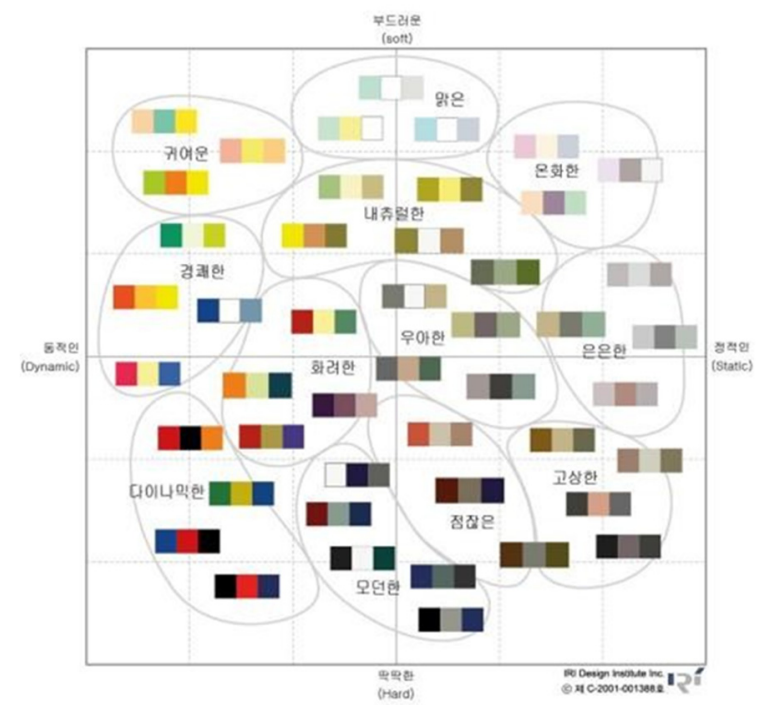

figure 2: I.R.I image scale

Source: IRI Color Research Institute, iricolor.com

\subsection{Adjective image scale}

Adjective Image Scale, When people talk about images about color, they usually use adjectives such as "cute" or "elegant one". As we study the relationship between color and image, the difference in meaning of adjectives, which is the bridge that connects the two, is determined by the "soft-hard" and "dynamic-static" axes used in our system (solid, white image scale). It can be made on top of). Understanding the adjective image scale (figure 3)

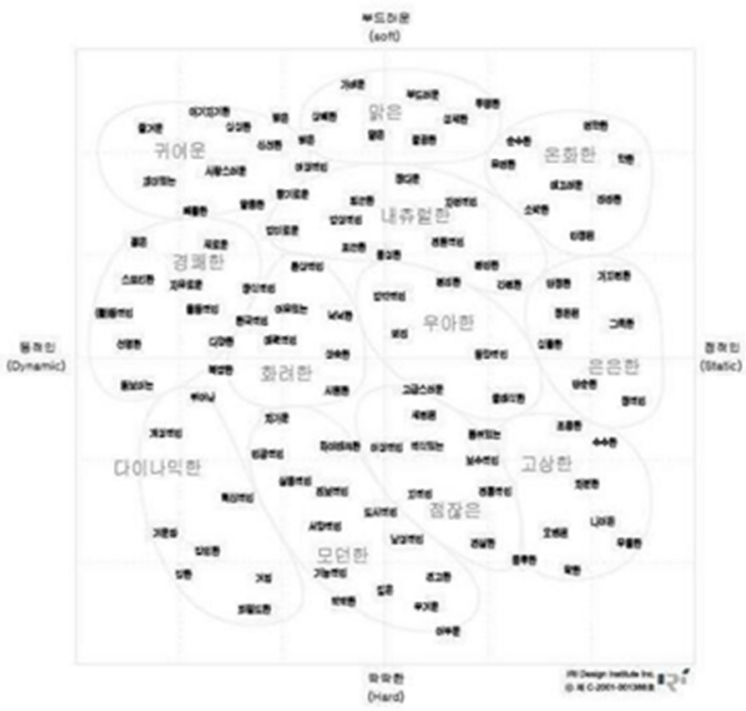

figure 3: Adjective image scale

Source: IRI Color Research Institute, iricolor.com

\subsection{Korean standard color}

The color analysis of Korean standard colors is a program developed as a project of "Diffusion of National Color Standards Implementation" conducted as part of the "2009 Standard Technology Improvement Project". This color analysis program is an application program that analyzes colors based on the Korean industrial standard (KS A 0062 display method by three attributes of colors) 22 along with 
the Korean color standard digital palette and supports communication in the design process. (figure 4)

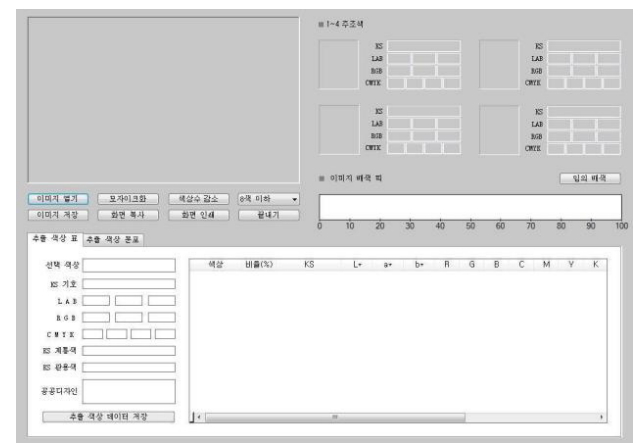

figure 4: Korean standard color

Color Analysis (KSCA) Source: National Institute of Technology and Standards

\section{Color design of cosmetic brand packaging design-take Korean cosmetics as an example}

Today's economic globalization, companies must survive in an internationally competitive environment, must have a good company brand image. Korea's most famous cosmetic brands, they all attach great importance to the design of the brand image, and a variety of customers. We try to do a set of designs for the group. Products used by customers of different genders, people and ages, designed in different series. The important design methods that usually distinguish them are: Color design. Designed in accordance with the consumer psychology and color preferences of this customer group, allowing consumers to empathize with products to promote sales.

\subsection{Nature Republic}

Nature Republic is a brand founded in 2009 when The Face Shop was acquired by LG H\&H, with middle board members. Nature Republic's symbol and logotype use green color as a nature-friendly concept, and the color of the package is mainly pastel-based and brown and greenlike colors felt in nature. Illustrations dominate as graphic elements, and photo cuts are rarely used in some body products. The motif of the illustration is mainly plants such as fruits and flowers, which can be used for cosmetics. The illustration technique is depicted in the form of emphasizing lines and emphasizing colors in simple patterns. Layouts can be classified into ones with horizontal and vertical arrangements in the font direction. The brand logo is placed at the top of the layout, the graphic image is placed in the middle or right, and the image is placed in the whole. The product name and product information typeface are mainly Gothic, giving a clean and modern feel. The shape of the container is different for each line and color.

For products from Nature Republicl, green is the primary color, the background color is mainly light green and white, and a small amount of brown and gray purple is used for decoration. As a result of analyzing the I.R.I hue and hue (Hue\&Tone), the background color was N9.5 achromatic area, the same as the main color. The secondary color appeared as a brightly colored BG area. The emphasis color appeared to be located in the YR area and the achromatic N4 area. In the adjective image scale analysis, the app launch icon was a light, colorful and elegant area, with keywords of idyllic, cool, oriental, and keywords of oriental, calm and cool were derived. In this color scheme, there is not only the harmonious aesthetics of similar colors, but also the competence of contrasting colors. (Table 1)

Table 1. Nature Republic Analysis Table

\begin{tabular}{|c|c|c|c|}
\hline \multicolumn{3}{|c|}{ Logo } & $\begin{array}{c}\text { Top selling product } \\
\text { photos }\end{array}$ \\
\hline \multicolumn{3}{|c|}{ NATURE REPUBLIC } & dis \\
\hline \multicolumn{3}{|c|}{ SCKA } & Hue \& Tone \\
\hline \multirow{2}{*}{ 쌕상 } & 비휼 $(\%)$ & KS & \multirow{6}{*}{ 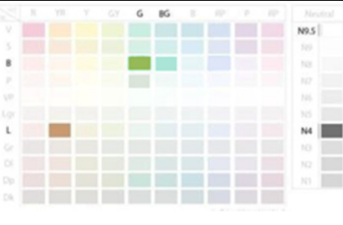 } \\
\hline & 81.51 & KS $10 \mathrm{GY} 9 / 1$ & \\
\hline 2 & 8.47 & KS $6.25 \mathrm{GY} 7 / 8$ & \\
\hline 3 & 5.49 & KS $7.5 \mathrm{GY} 4 / 8$ & \\
\hline 4 & 4.09 & KS $7.5 \mathrm{GY} 6 / 8$ & \\
\hline 5 & 0.29 & KS $10 R$ R/4 & \\
\hline \multicolumn{3}{|c|}{ I.R.I image scale } & Adjective image scale \\
\hline & • & $\because \because=$ & 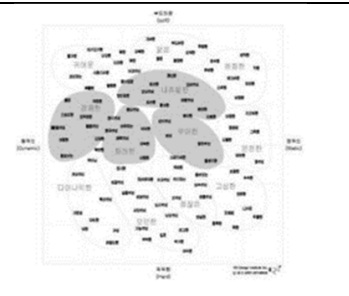 \\
\hline
\end{tabular}

\subsection{The Face Shop}

The Face Shop, a subsidiary of LG Life Health, has the highest sales along with Missha among brand shops. It has a brand concept that puts the beauty of nature in products and returns them to customers. The brand logo is a concise and straight Gotham font that symbolizes nature using green and yellow green colors as a modern word mark. The package color is pastel and various colors such as green, pink, purple, and black are used. As graphic elements, illustrations are used instead of photographs, and natural materials such as flowers, fruits, and leaves are mainly used as materials. To achieve.

The Face Shop analyzed I.R.I hue and hue (Hue\&Tone), and the background color, auxiliary color and main color were the same N9.5 achromatic area. The highlight colors were YR zone, R zone, GY zone, PB zone, and RP zone. In the adjective image scale analysis, the execution icon was cute, elegant, clear and colorful zone, and the keywords of bright, fresh, mature, oriental were derived The screen is cute and elegant, with a clear and colorful area, and the keywords of bright, fresh, mature, oriental, cheerful were derived. (Table 2) 
Table 2. The Face Shop Analysis Table

\begin{tabular}{|c|c|c|c|}
\hline \multicolumn{3}{|c|}{ Logo } & Top selling product photos \\
\hline \multicolumn{3}{|c|}{ THEFACESHOP } & 围围 \\
\hline \multicolumn{3}{|c|}{ SCKA } & Hue \& Tone \\
\hline 색상 & 비율 $(\%)$ & KS & \multirow{6}{*}{ 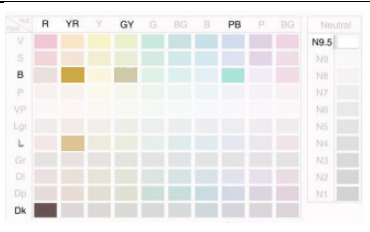 } \\
\hline 1 & 61.56 & KS 10R 9/1 & \\
\hline 2 & 25.32 & KS 8.75 Y $8 / 2$ & \\
\hline$\frac{3}{4}$ & 10.02 & KS $3.75 Y 7 / 8$ & \\
\hline$\frac{4}{5}$ & & KS $1.25 Y 8 / 4$ & \\
\hline 6 & & KS 7.5YR 5/6 & \\
\hline \multicolumn{3}{|c|}{ I.R.I image scale } & Adjective image scale \\
\hline$=$ & $\therefore:$ & 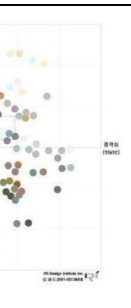 & 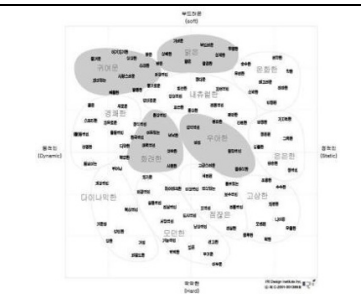 \\
\hline
\end{tabular}

\subsection{Skin Food}

Skin Food is a cosmetic brand established in 2004 with the concept of tasty cosmetics made from delicious food'. The brand concept of food cosmetics is gaining popularity in line with the well-being trend, and is popular with young women with food pictures such as brown sugar, carrots, tomatoes, apples, and the cute baby angel brand logo. The brand logo has a retro logotype, a baby angel silhouette, and the phrase since 1957 in a circular frame. Lee Moongu contains the meaning of a traditional cosmetic product that continues the predecessor of Skin Food, Pearis. The package color is dominated by the pastel series, and the difference from other brands is the diversification of the container shape. In accordance with the concept of breaking away from the stereotype of "food eaten by skin = cosmetics", the shape of the container is interesting because it mimics the shape used in juice bottles, water bottles, sake bottles, sauce bottles, etc. Most of the graphic elements are illustrative, mainly fruits, and vegetables, honey, flowers, berries, and mushrooms. The illustration technique can be divided into an illustration expressed only with lines and an illustration that emphasizes color mainly on the side, and the product label has an illustration of fruits or vegetables as ingredients.

I.R.I Hue\&Tone analysis results show that the main color, the background color, and the auxiliary color are the same color and are located in the N9.5 area of the achromatic tone. The accent color is located in the light YR area and the achromatic color N2 area.

In the adjective image scale analysis, the app launch icon is in a cute, modern, elegant area, and appears as a joyful, dark, oriental keyword, and the adjective image on the app screen is located in a clear, modern and elegant area, shallow, dark, and It is derived as an oriental keyword. (Table 3)
Table 3. Skin Food Analysis Table

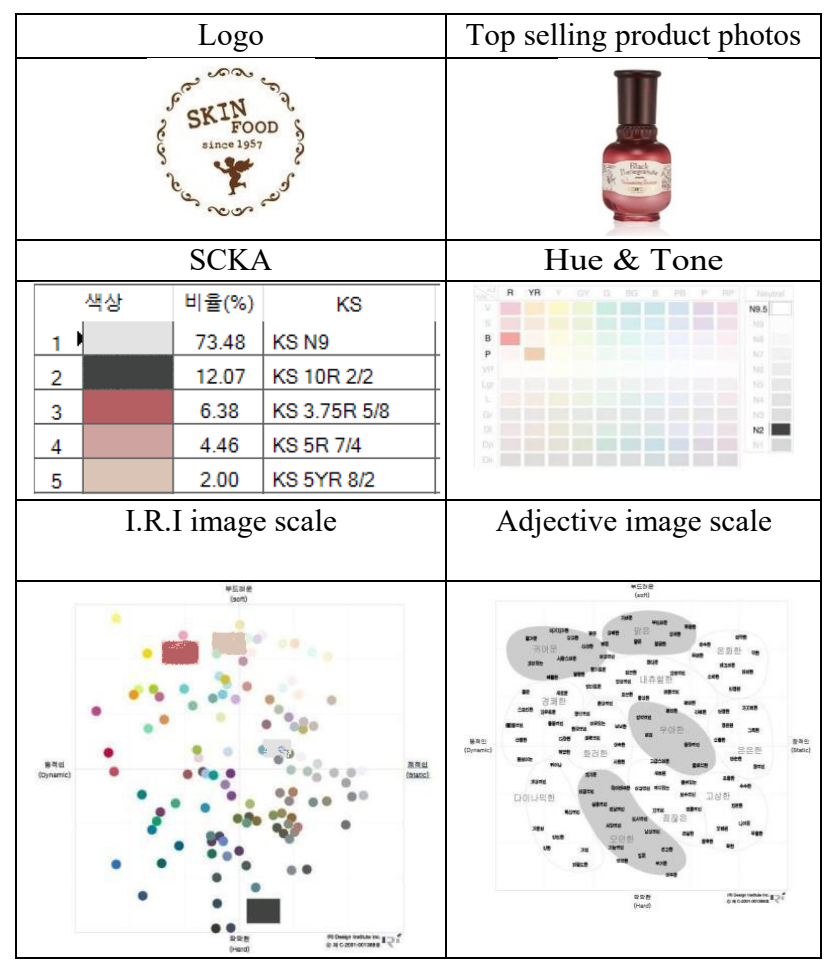

\subsection{Etude}

Etude is a subsidiary of Amore Pacific, founded in 1985 in French, meaning Chopin's beautiful practice song. The brand concept is the image of a young woman who freely, confidently, and actively seeks a hidden princess inside herself. In line with this concept, we are developing princess marketing that makes customers feel that they have become princesses. The brand logo is entirely pink, and the overall shape of the figure located at the top of the logo type is a pumpkin carriage, implying that it leads customers to Etude. The rhombus shape at the top represents the girl's sweet dreams and longing for beauty, and the heart shape in the center symbolizes a pure and beautiful heart and longing for the world. The package colors are mainly pastel colors, reds, and blacks.

As a result of analyzing the I.R.I hue and hue (Hue\&Tone), the background color, the secondary color and the main color were the same N9.5 achromatic area. The highlight colors were $\mathrm{YR}$ zone, $\mathrm{R}$ zone, $\mathrm{B}$ zone, $\mathrm{PB}$ zone, RP zone and achromatic N9. In the adjective image scale analysis, the execution icons were cute and elegant zones and bright, oriental keywords were derived, and the app screen was elegant and With colorful, cute and natural areas, keywords of bright, fresh, mature, oriental, and traditional were derived. (Table 4) 
Table 4. Etude Analysis Table

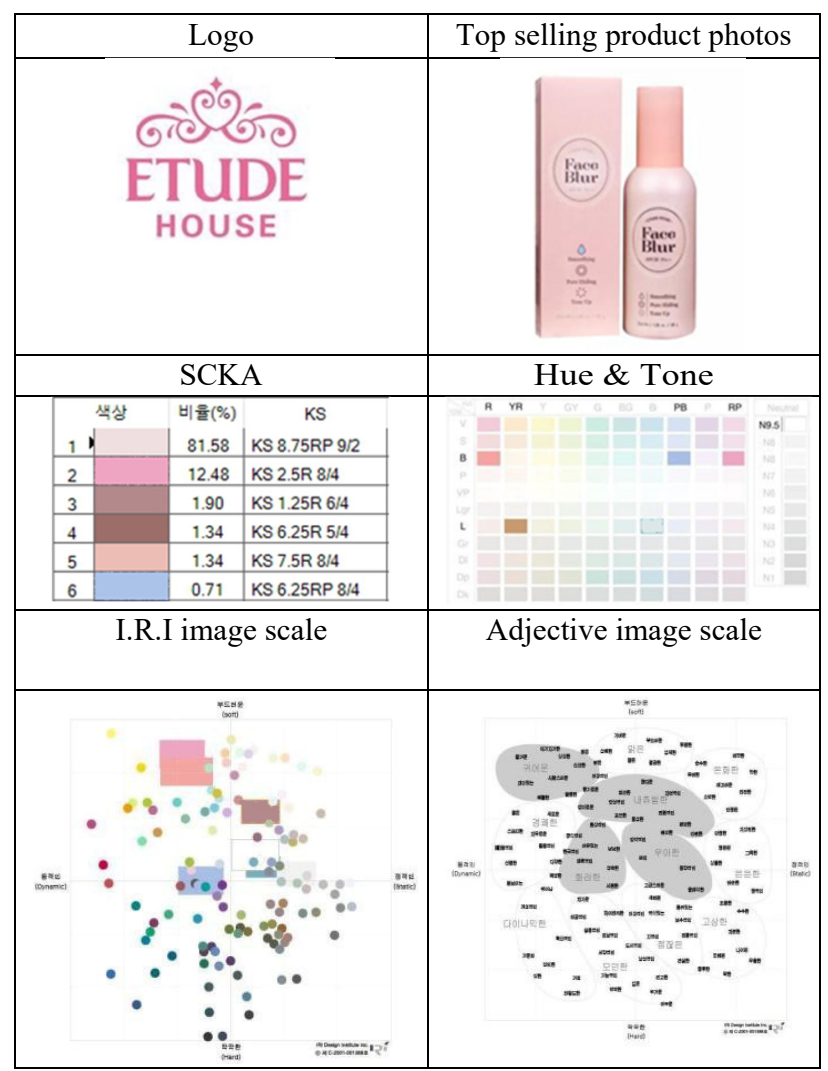

\subsection{Too cool for school}

Too cool for school means to be cool, cool, or too cool in a group. It is a brand that expresses differentiated emotional thoughts (unique but unusual, cool things, superior things, not pretty and cute things) and feeling different from the existing cosmetic brands centered on star marketing. The brand logo is a black logo inside a yellow square. It is written concisely by type and takes a form that breaks away from the concept of a cosmetic brand logo. It goes well with the store with a unique atmosphere like a mysterious flea market. The color of the package is white, gray, and light blue as basic colors.

As a result of analyzing R.I hue and hue (Hue\&Tone), it was found that the background color and the auxiliary color were the same N9.5 achromatic area. The accent color is rich and it was found to be located in the PB area, the P area, the B area, the GY area, the YR area, and the $\mathrm{R}$ area. In the adjective image scale analysis, the execution icon is an active, oriental, dark area with light, modern and elegant areas. (Table 5)

Table 5. Too cool for school Analysis Table

\begin{tabular}{|l|c|}
\hline \multicolumn{1}{|c|}{ Logo } & $\begin{array}{c}\text { Top selling product } \\
\text { photos }\end{array}$ \\
\hline toO & \\
COOl \\
fOr \\
SChOOl
\end{tabular}

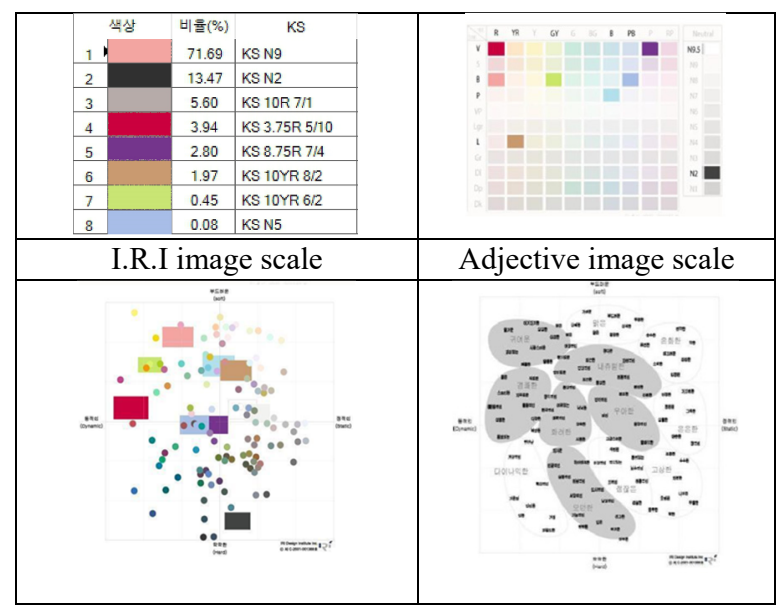

\section{Color summary of Korean cosmetic packaging design}

According to the color analysis of the five brands, the main colors are: white, pink, light green, dark green, blue, purple, silver, beige, turquoise, flesh, green, sky blue, sky blue, brown, lemon yellow, orange, Yellow, light green, pink, dark red, black, red, gray.

(Table 6)

Table 6. Color summary table

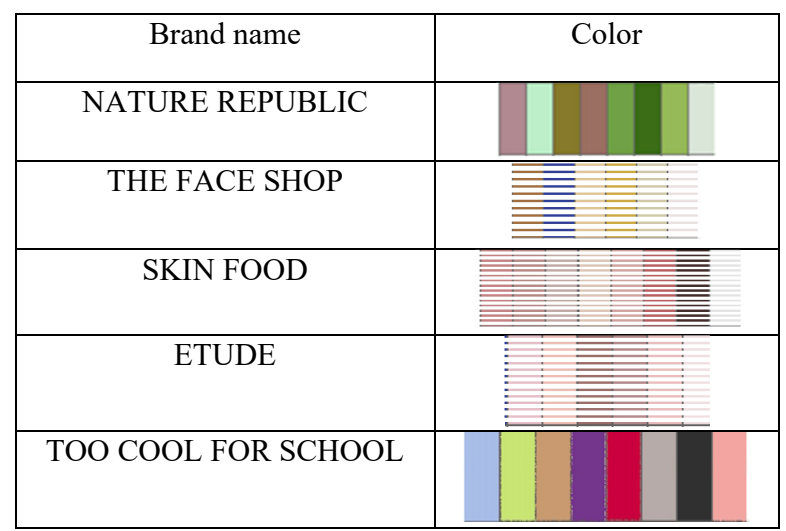

The monochromatic image scale with the highest ratio shown in the above five color analysis of Korean cosmetic packaging brands is located on the dynamic axis. The adjective image scale often appeared in elegant and cute areas. Then the keywords "fresh" and "bright" often appear in color matching in cosmetic packaging designs and are almost the same throughout the color composition. The warm color scheme of the color system makes the product feel clean and refreshing, and there are also cosmetic packaging designs that add rich colors to the main color to make the photo look more vivid and rich. (Table 7) 
Table 7. Color adjective summary analysis table

\begin{tabular}{|c|c|c|c|c|c|}
\hline brand & $\begin{array}{c}\text { Nature } \\
\text { Republi } \\
\text { c }\end{array}$ & $\begin{array}{l}\text { The } \\
\text { Face } \\
\text { Shop }\end{array}$ & $\begin{array}{l}\text { Skin } \\
\text { Food }\end{array}$ & Etude & $\begin{array}{c}\text { Too cool } \\
\text { for } \\
\text { school }\end{array}$ \\
\hline $\begin{array}{c}\text { Brand } \\
\text { Concept } \\
\text { Keywor } \\
\text { ds }\end{array}$ & nature & nature & $\begin{array}{c}\text { natur } \\
\mathrm{e}\end{array}$ & $\begin{array}{c}\text { Prince } \\
\text { ss }\end{array}$ & $\begin{array}{c}\text { Personali } \\
\text { ty }\end{array}$ \\
\hline $\begin{array}{c}\text { adjectiv } \\
\mathrm{e}\end{array}$ & $\begin{array}{l}\text { fresh } \\
\text { bright }\end{array}$ & $\begin{array}{l}\text { bright } \\
\text { matur } \\
\mathrm{e} \\
\text { fresh } \\
\text { cheerf } \\
\text { ul }\end{array}$ & $\begin{array}{l}\text { happ } \\
\text { y } \\
\text { dark } \\
\text { fresh }\end{array}$ & $\begin{array}{l}\text { bright } \\
\text { lively } \\
\text { fresh } \\
\text { warm }\end{array}$ & $\begin{array}{c}\text { Active } \\
\text { Oriental } \\
\text { Dark } \\
\text { cool }\end{array}$ \\
\hline $\begin{array}{c}\text { Cold } \\
\text { color } \\
\text { system }\end{array}$ & $\begin{array}{l}\text { Warm } \\
\text { color } \\
\text { system } \\
\text { Multicol } \\
\text { or } \\
\text { system }\end{array}$ & $\begin{array}{c}\text { Warm } \\
\text { color } \\
\text { syste } \\
\text { m } \\
\text { Cold } \\
\text { color } \\
\text { syste } \\
\text { m }\end{array}$ & $\begin{array}{c}\text { War } \\
\mathrm{m} \\
\text { color } \\
\text { syste } \\
\mathrm{m} \\
\text { Cold } \\
\text { color } \\
\text { syste } \\
\mathrm{m}\end{array}$ & $\begin{array}{c}\text { Warm } \\
\text { color } \\
\text { syste } \\
\text { m } \\
\text { Cold } \\
\text { color } \\
\text { syste } \\
\text { m }\end{array}$ & $\begin{array}{c}\text { Cold } \\
\text { color } \\
\text { system }\end{array}$ \\
\hline
\end{tabular}

\section{Conclusion}

In the modern cosmetics industry, packaging design is the first recognized form of consumers and brand marketing activities.

It is used as an important tool in Therefore, the purpose of this study is to analyze the color design of cosmetic brands with high brand value to understand the color design packaging direction of the brand. This article is too cool for Nature Republic, The Face Shop, Skin Food, Etude, and School. We analyze 5 Korean cosmetic packaging color designs. According to the research results:

(1) It turns out that the packaging color design of the above 5 brands is better handled in the relationship between the brand meaning and concept, but there is no significant difference in the packaging color design of the 3 brands, which has the essence as the brand concept. The color perception rate is not high The three brands are mainly large-scale bright background colors and are designed in fresh green, yellow and orange, giving consumers a clean, natural and bright feeling. The designs of these three cosmetic brands impress consumers through the design and design of cosmetics.

(2) Visually and wisely, the most common color scheme of Korean cosmetic brands is to separate colors that are similar to complementary colors. Mainly used for warm color series. According to the different series, different colors are designed, and the young series generally uses bright and vibrant colors such as green, yellow and pink as the primary color, giving people a fresh, cute, natural and soft feel. Collections that emphasize individuality and efficiency usually use dark colors such as black, red and purple as their primary colors, giving people a sense of elegance, mystical and noble. These color designs help consumers intuitively select the properties of their products through color.

(3) In the competition between global cosmetic brand companies and the rapidly changing social and cultural environment, Korean cosmetic brands should pay attention to the brand's color design and actively use individual colors as an effective means to establish the brand image. Those who recognize the brand concept of cosmetics will help develop the brand.

\section{REFERENCES}

1. $\mathrm{Hu}$ Hongzhong, Wang Xinxia, et al. Reasonable application of personality beauty in cosmetic packaging design for 20-year-old Korean women[J]. Packaging Engineering. 2010

2. Duan Xiaoming. Analysis of cosmetic packaging design and female consumer psychology[J].2012

3. Barbara E. Kahn, [Global brand power], Wharton Digital Press Philadelphia, 2013.

4. Sam Abbott, [Terry Hoeye, Nike: The Global Brand], Deep Dive Outline, 2013.

5. Wang Lei. Research on the packaging design of cosmetics series[D]. Jilin: Jilin University. 2019 